\title{
Optimization of Gear Transmission Parameters and Dynamic Performance Based on Efficiency Improvement
}

\author{
Lingyan ZHANG, Shuicai QIU*
}

\begin{abstract}
The machinery industry is changing with each passing day, and the speed of machinery is getting higher and higher. The dynamic behavior and working performance of the gear system have an important influence on the entire system. Therefore, the research on the dynamic characteristics of the gear transmission system is of great significance to improving the stability and safety of the system. This article focuses on the establishment of dynamic model, the analysis and determination of incentive factors, and the solution of dynamic equations to optimize the gear transmission parameters and the efficiency improvement. After the optimization, the optimized values of the design variables were adjusted and the unit characteristics were redefined. Then the same analysis method was used to analyze the dynamic response and state-owned characteristics of the gear transmission system under the same working conditions. Therefore, the requirements for the dynamic performance of gears in mechanical transmission are more prominent.
\end{abstract}

Keywords: dynamic performance; dynamic response; efficiency improvement; gear transmission

\section{INTRODUCTION}

Gear system is the most widely used power and motion transmission device in various machinery and equipment, and its dynamic behavior and working performance have an important impact on the entire machine. The development of modern industry, such as the gear devices of various power transmission machinery in the automobile, locomotive, mining, metallurgy, electric power, petroleum, chemical and other industries, in order to improve efficiency, generally tends to develop in the direction of high speed, heavy load, and miniaturization [1,2]. The main characteristics of modern gear transmission are as follows: high linear speed brings greater transfer, noise, and dynamic load, which affects the safety and stability of the entire unit. The tooth surface bonding and wear failure increase significantly; the force deformation and thermal deformation of the gear are relatively large [3]. The high power transmission requires high transmission efficiency of the gear. Because gears that operate under high-speed and heavy-duty conditions have become a key basic part of large-scale complete sets of equipment in various sectors of the national economy, our backward technology has to spend a lot of foreign exchange to import foreign gears. Therefore, high-quality and high-performance gear with dynamic performance has been imminent in front of the gear industry.

Currently, gear mechanisms are widely used in various industries. The research on the structural design, processing technology, lubrication and fatigue life has been more in-depth [4]. In the design process, the efficiency range is generally determined by checking the table of accuracy grade and lubrication conditions. In this way, the average value of the rough selection cannot reflect the influence of gear structure parameters on transmission efficiency. However, existing studies focused on average transmission efficiency and did not reflect the instantaneous efficiency changes during the meshing process, and did not clarify the gear structure parameters and movement [5].

At the same time, the influence of non-linear factors such as tooth flank clearance, tooth removal, friction, and lubrication is also involved [6]. With the development of modern gear transmission technology, higher and higher requirements are put forward for its dynamic performance, and the requirements for the strength, transfer and noise of the gear transmission are more stringent, prompting people to conduct in-depth research on gear dynamics. In recent decades, many research results have been made in the dynamic characteristics analysis of gear transmission pairs and gear transmission systems inside gear transmissions, and they have been gradually applied to the dynamic design of gear pairs.

To sum up, in view of the shortcomings of related research, in order to make the calculation of gear transmission efficiency more in line with the actual situation, this article calculates the instantaneous meshing efficiency of the meshing point on the left and right sides of the node, and integrates the meshing line length. The average transmission efficiency of the gear pair in the meshing line length range is obtained, and the value ranges of the variables such as the number of teeth, the transmission ratio, and the friction factor are listed. The expression is used as the objective function, and the calculation is obtained by the penalty function outer point method. The maximum value of the average efficiency and the corresponding optimal parameters has certain guiding significance for engineering design. In short, systematic and comprehensive analysis of the dynamic performance of gear transmissions has become a new trend in gear dynamics research. However, engaging in the dynamic design of gear transmission systems still needs to conduct in-depth research on its dynamic design.

\section{INSPECTION CONTENT AND RELATED METHODS 2.1 Dynamic Model of Gear Transmission System}

Gear a and gear $\mathrm{d}$ are fixedly connected to the two ends of the rigid shaft $A$, the gear $b$ is sleeved outside the elastic shaft $\mathrm{B}$, and the gear $\mathrm{C}$ is fixedly connected to the left end of the elastic shaft B. The motor adopts a shell suspension device, and the output torque of the motor is obtained through a gear, a rack mechanism, and a sensor 6. The structure is shown in Fig. 1. The application of the closing torque is obtained through the handwheel 7 and the spiral groove loader 5 . The structure of loading device 5 is shown 
in Fig. 1. When loading, turn the hand wheel 7 to rotate the end screw 7'. Push the nut sleeve 5 of the loader to move straight to the left and pass through the thrust bearing 4 , so that the loading sleeve 3 also moves to the left, and the loading sleeve moves to the left. On the one hand, the pin roller set 2 fixed on it slides along the groove in the spiral groove sleeve 1 fixed on the gear $b$. On the other hand, the key on the end of the elastic shaft of the loading sleeve 3 slips, and the result of the slip causes the elastic shaft to produce relatively torsional deformation, thereby generating a loading force on the gear.
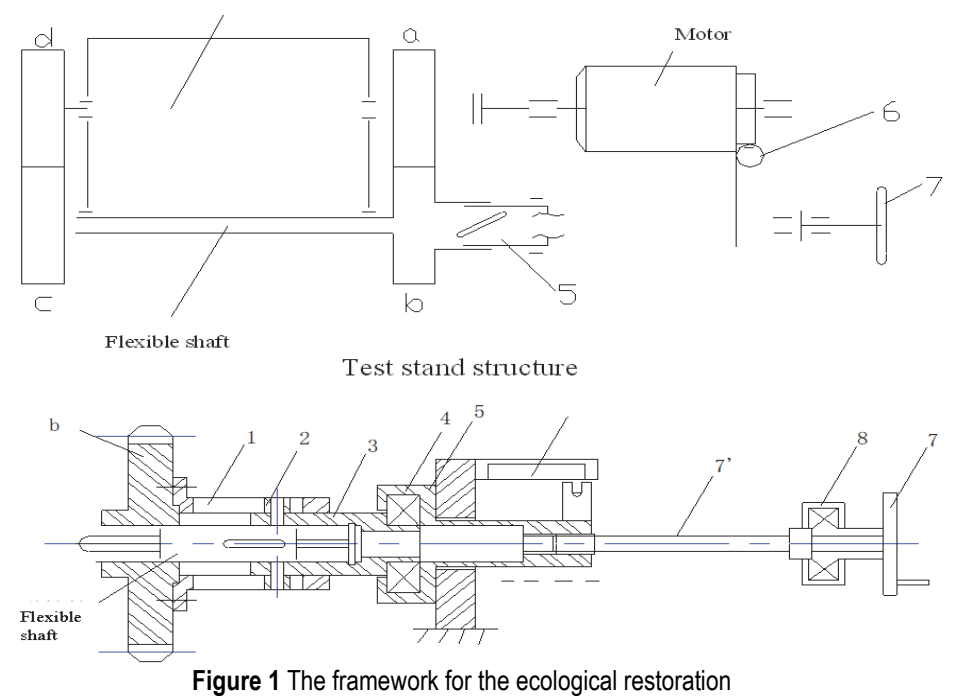

Figure 1 The framework for the ecological restoration

\begin{tabular}{|c|c|c|c|c|}
\hline NO. & \multicolumn{2}{|c|}{ Project } & Code & Calculation formula and calculation result \\
\hline \multirow{2}{*}{1} & \multirow{2}{*}{ Number of teeth } & Gear 5 & $z_{5}$ & ( \\
\hline & & Gear 6 & $z_{6}$ & 43 \\
\hline 2 & \multicolumn{2}{|l|}{ Modulus } & $m$ & 2.4 \\
\hline 3 & \multicolumn{2}{|l|}{ Pressure angle } & $\alpha$ & $24^{\circ}$ \\
\hline 4 & \multicolumn{2}{|l|}{ Addendum height coefficient } & $h_{\mathrm{a}}{ }^{*}$ & 1 \\
\hline 5 & \multicolumn{2}{|l|}{ Head clearance coefficient } & $c^{*}$ & 0.5 \\
\hline 6 & \multicolumn{2}{|l|}{ Standard center distance } & $a$ & $a=0.5 \cdot m \cdot\left(\mathrm{z}_{5}+\mathrm{z}_{6}\right)=57$ \\
\hline 7 & \multicolumn{2}{|l|}{ Actual center distance } & $a^{\prime}$ & 60 \\
\hline 8 & \multicolumn{2}{|l|}{ Engagement angle } & $\alpha^{\prime}$ & $\alpha^{\prime}=\arccos \left(a \cdot \cos \alpha / a^{\prime}\right)=26.8^{\circ}$ \\
\hline \multirow{2}{*}{9} & \multirow{2}{*}{ Modification coefficient } & Gear 5 & $x_{5}$ & 0.660 \\
\hline & & Gear 6 & $x_{6}$ & 1.095 \\
\hline \multirow{2}{*}{10} & \multirow{2}{*}{ Tooth top height } & Gear 5 & $h_{\mathrm{a} 5}$ & $h_{\mathrm{a} 5}=h_{\mathrm{a} 6}=h_{\mathrm{a}}{ }^{*} \cdot m=2.9$ \\
\hline & & Gear 6 & $h_{\mathrm{a} 6}$ & $h_{\mathrm{a} 5}=h_{\mathrm{a} 6}=h_{\mathrm{a}}^{*} \cdot m=3.7$ \\
\hline \multirow{2}{*}{11} & \multirow{2}{*}{ Tooth root height } & Gear 5 & $h_{\mathrm{f} 5}$ & $h_{\mathrm{f} 5}=h_{\mathrm{f} 6}=m \cdot\left(h_{\mathrm{a}}{ }^{*}+c^{*}\right)=1.20$ \\
\hline & & Gear 6 & $h_{\mathrm{f} 6}$ & $h_{\mathrm{f} 5}=h_{\mathrm{f} 6}=m \cdot\left(h_{\mathrm{a}}^{*}+c^{*}\right)=0.16$ \\
\hline \multirow{2}{*}{12} & \multirow{2}{*}{ Diameter of index circle } & Gear 5 & $d_{5}$ & $d_{5}=m \cdot z_{5}=26$ \\
\hline & & Gear 6 & $d_{6}$ & $d_{6}=m \cdot z_{6}=84$ \\
\hline \multirow{2}{*}{13} & \multirow{2}{*}{ Addendum circle diameter } & Gear 5 & $d_{\mathrm{a} 5}$ & $d_{\mathrm{a} 5}=d_{5}+2 \cdot h_{\mathrm{a} 5}=33.7$ \\
\hline & & Gear 6 & $d_{\mathrm{a} 6}$ & $d_{\mathrm{a} 6}=d_{6}+2 \cdot h_{\mathrm{a} 6}=93.4$ \\
\hline \multirow{2}{*}{14} & \multirow{2}{*}{ Tooth root circle diameter } & Gear 5 & $d_{\mathrm{f} 5}$ & $d_{\mathrm{f} 5}=d_{5}-2 \cdot h_{\mathrm{f} 5}=25.7$ \\
\hline & & Gear 6 & $d_{\mathrm{f} 6}$ & $d_{\mathrm{f} 6}=d_{6}-2 \cdot h_{\mathrm{f} 6}=85.7$ \\
\hline \multirow{2}{*}{15} & \multirow{2}{*}{ Addendum pressure angle } & Gear 5 & $\alpha_{\mathrm{a} 5}$ & $\alpha_{\mathrm{a} 5}=\arccos \left(d_{5} \cdot \cos \alpha / d_{\mathrm{a} 5}\right)=38.5^{\circ}$ \\
\hline & & Gear 6 & $\alpha_{\mathrm{a} 6}$ & $\alpha_{\mathrm{a} 6}=\arccos \left(d_{6} \cdot \cos \alpha / d_{\mathrm{a} 6}\right)=30.5^{\circ}$ \\
\hline 16 & \multicolumn{2}{|l|}{ Coincidence degree } & $\varepsilon$ & $\left(z_{5} \cdot\left(\tan \alpha_{\mathrm{a} 5}-\tan \alpha^{\prime}\right)+z_{6} \cdot\left(\tan \alpha_{\mathrm{a} 6}-\tan \alpha^{\prime}\right)\right) / 2 \pi=1.16$ \\
\hline
\end{tabular}

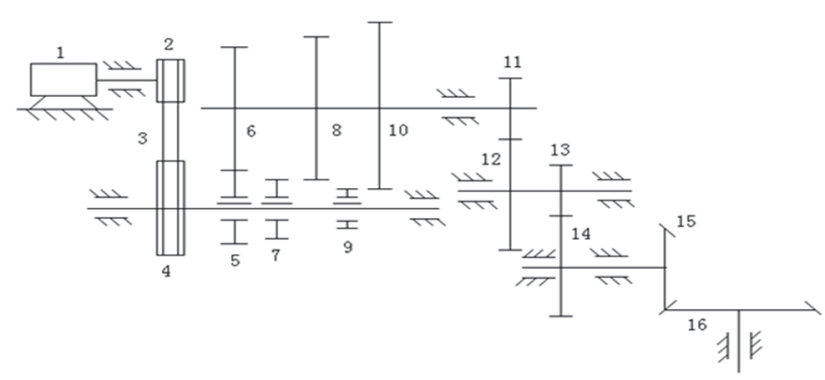

Figure 2 Gear transmission system

Due to the circumferential, radial and axial transfers produced by the double circular arc gear when it is working, although the circumferential transfer is the most important, that is, the main form of transfer is torsional transfer, in fact, the direction transfer of the drive shaft also affects the torsional transfer, as shown in Fig. 1. Based on the above analysis, the lumped parameter method is used to establish its mechanical model, as shown in Fig. 2.

According to the requirements for the number of gear teeth in the sliding gear transmission system, gear 5 , gear 6 , gear 7 , gear 8 , gear 9 and gear 10 can be roughly selected as height and angle shift gears. The number of teeth: $z_{5}=$ $14, z_{6}=43, z_{7}=12, z_{8}=48, z_{9}=11$ and $z_{10}=49$; their addendum height coefficient $=1$, radial clearance coefficient $=0.25$, index circle pressure angle $=20^{\circ}$, actual center distance $=60 \mathrm{~mm}$.

According to the requirement of gear teeth number in the fixed-axis gear transmission system, gear 11, gear 12 , gear 13 and gear 14 are selected as highly modified gears, 
the number of teeth: 14,19 . Their addendum height coefficient $=1$, radial clearance coefficient $=0.25$, index circle pressure angle $=20^{\circ}$, actual center distance $=51 \mathrm{~mm}$ [7]. Round hammer gears: 15 and 16 are selected as standard gear 17 , gear 26 , addendum height coefficient $=1$, radial clearance coefficient $=0.2$, index circle pressure angle $=20^{\circ}$ (equal to meshing angle).

From the above design parameters, the geometric dimensions of gear 5 and gear 6 , gear 7 and gear 8, gear 9 and gear10 can be obtained, see Tab. 1.

\subsection{Calculation of Transmission Efficiency}

The meshing of the involute gear is shown in Fig. 3. In the figure, $r_{1}, r_{\mathrm{b} 1}$ and $r_{2}, r_{\mathrm{b} 2}$ are the pitch circle and base circle radius of the driving wheel 1 and the driven wheel 2 .

--- $A B$ is the ideal meshing line,

--- $E_{1} E_{2}$ is the actual meshing line, the line segment between node $K$ and the instantaneous meshing point $F$.

--- $K F$ is equal to $L$ in value.

--- $C D$ is the line segment, where there is the resultant force of the normal pressure and friction at the meshing point.

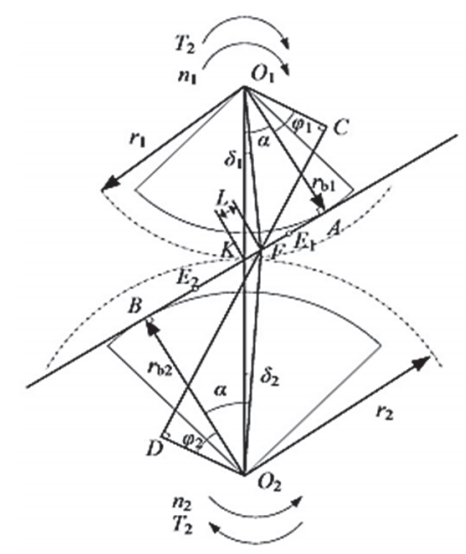

Figure 3 Schematic diagram of gear anastomosis

\section{OPTIMIZATION DESIGN OF GEAR TRANSMISSION}

The optimization design of gear transmission is static optimization design, because the objective function and constraint function of the optimization design are both static performance indicators, that is, the transfer characteristics generated during gear operation are not considered. People have higher and higher requirements for the dynamic performance of gear transmissions [8]. The difference between the latter and the former is that the constraint function is not an instantaneous dynamic response constraint function, but the maximum or cumulative value of the dynamic performance index in a meshing period. Due to the immature research on the optimization design of the transient constraint dynamic response at home and abroad, there are still practical difficulties, and the current research is mainly focused on the dynamic performance optimization design.

\subsection{Constructing the Mathematical Model of the Multi- Stage Gear Transmission System}

According to stiffness characteristics, there is a certain difference between multi-stage gear transmission and general gear transmission, and the main purpose of installing radial meshing multi-stage gear transmission between the load and the actuator is to transmit power and realize movement, so the impact of elasticity and backlash between teeth must be considered [9]. By comprehensively considering the effects of elasticity and backlash between teeth, a mathematical model is constructed. The IL in the model is the load inertia, and IM is the inertia of the motor rotor and wave generator. The rotation angle $\varphi M(t)$ of the motor is calculated and the rotation angle to the output shaft is $\varphi M(t)=\varphi M(t) / i h$.

From the above formula, the effects of component elasticity and backlash between teeth are fully considered, which a nonlinear function is. In a multi-stage gear transmission system, the system equivalent of the motor to the load is the link of two elastic elements, which separates the movement of the concentrated mass by the gap. Ii in the model is the inertia of IM converted to the output shaft, $\varphi(i t)$ and $T_{\mathrm{i}}$ are the input torque and rotation angle converted to the output end.

\subsection{Working Principle Diagram of the Experimental Platform}

Mechanical transmission efficiency is an important index to evaluate the comprehensive performance of mechanical transmission devices. We guide that the input power of the mechanical transmission system is equal to the sum of the output power and the internal power loss, namely $P_{\mathrm{i}}=P_{0}+P_{\mathrm{f}}$.

Where: $P_{\mathrm{i}}$ is the input power, $P_{0}$ is the output power, and $P_{\mathrm{f}}$ is the loss power. Then the mechanical efficiency $\eta$ is $\eta=P_{0} / P_{\mathrm{i}}$.

According to the knowledge of mechanics, if the torque of the mechanical transmission is $M$ and the speed is $n$, the corresponding power has the following relationship.

$$
P=\frac{M n}{9550}
$$

In the formula: $n$ is the speed of the transmission machinery.

Therefore, the transmission efficiency can also be expressed as follows.

$\eta=\frac{M_{0} \cdot n_{0}}{M_{\mathrm{i}} \cdot n_{\mathrm{i}}}$

Therefore, we only need to use the instrument to measure the input and output torque and speed of the tested transmission to calculate the transmission efficiency.

The working principle of the mechanical transmission performance comprehensive test bench is shown in the figure below. Through the measurement of torque and speed, the mathematical relationship between torque, speed, and power is used to indirectly derive the power value. Through the corresponding control of the motor and load, the corresponding change trend of speed, torque, and power is observed and analyzed. The input power and output power of the reducer are measured and analyzed, 
and the efficiency of the reducer and its change trend with different conditions are obtained.

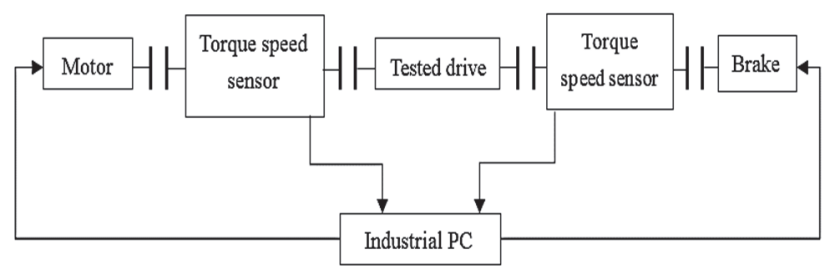

Figure 4 Power-efficiency diagram of gear-belt transmission

The mechanical transmission performance comprehensive test bench adopts a modular structure, which is composed of different transmission devices, couplings, motors, magnetic powder brakes, and industrial computers [11]. The components of the experimental program include three-phase AC motor, coupling, gear box, belt drive, torque speed sensor, magnetic powder brake and industrial computer.

The hardware composition of the test bench is as follows:

1: Three-phase asynchronous motor 2: Coupling 3: Torque speed sensor 4: Tested transmission 5: Magnetic powder brake 6: Power console 7: Pedestal.

The performance parameters of each part are as follows:

The power part includes JW5624 three-phase asynchronous motor: rated power $120 \mathrm{~W}$, synchronous speed $1400 \mathrm{r} / \mathrm{min}$, input voltage $380 \mathrm{~V}$. The test part includes NJ0 torque speed sensor: rated torque $20 \mathrm{Nm}$, working speed $0 \sim 6000 \mathrm{r} / \mathrm{min}$, number of teeth (inner) 120 [12]. NJ10 torque speed sensor: rated torque is $90 \mathrm{Nm}$, working speed is at $0 \sim 5000 \mathrm{r} / \mathrm{min}$, number of teeth (inner) is 90 [13]. The tested part includes a spur gear reducer, and gear- belt drive. The braking part includes CZ6 magnetic powder brake: rated torque $50 \mathrm{Nm}$, rated power $3.5 \mathrm{~kW}$, flux current $0 \sim 0.3 \mathrm{~A}$.

\subsection{Experimental Instruments and Equipment 3.3.1 Optimization of First-Stage Cylindrical Spur Gear Transmission}

According to Eq. (1), write its objective function as:

$F\left(z_{1}, i, \alpha, f\right)=\max (-\eta)$

The value of the friction factor $f$ varies according to the application and cost, and this optimization takes 0.01 [14]. Combined with the actual situation, the constraints are listed as follows.

$$
\begin{aligned}
& 17<z_{1}<30 \\
& 1<i<10 \quad f=0.01 \\
& 15^{\circ}<\alpha<25^{\circ}
\end{aligned}
$$

The optimization method is the penalty function outer point method, taking the initial point $\mathrm{I} 0\left(z_{1}=20, I=0.2, \alpha\right.$ $\left.=20^{\circ}, f=0.01\right)$, the initial value of the penalty factor $r_{0}=$ 1 , the amplification factor $c=10$, Convergence accuracy $\varepsilon$ $=0.0001$.

This paper uses MATLAB programming to optimize the calculation $[13,14]$, a total of 7 iterations, the maximum value of output $F=0.9956$, and the best point is $z_{1}=23.22476, i=3.568301, \alpha=20.65447^{\circ}$ and $f=0.01000$.

For data rounding processing, it takes $F=0.996, z_{1}=$ $23, i=3.5, \alpha=20^{\circ}$ and $f=0.01$.

\subsubsection{Two-Stage Cone-Cylindrical Gear Transmission Optimization}

The derivation is optimized for the first-level standard cylindrical gear, which has certain limitations in practical applications, so the second-level cone-cylindrical reducer is now optimized for the design.

Convert the bevel gear in the two-stage conecylindrical reducer into an equivalent cylindrical gear, the equivalent number of teeth $z_{\mathrm{v} 1}=z_{1} \cdot \cos \delta, \delta$ is the indexing cone angle, and the equivalent friction factor is $f_{\mathrm{v} 1}=f_{1}$.

Convert helical cylindrical gear into equivalent gear, the equivalent number of teeth is $z_{\mathrm{v} 2}=z_{2} \cdot \cos 3 \beta$, where $\beta$ is the helix angle, and the equivalent friction factor is $f_{\mathrm{v} 2}=$ $f_{2} \cdot \cos \beta[15]$. Then the total efficiency of the secondary gear meshing is $\eta_{\text {total }}=-\eta_{1}\left(z_{\mathrm{v} 1}, i_{1}, \alpha_{1}, f_{\mathrm{v} 1}\right)-\eta_{2}\left(z_{\mathrm{v} 2}, i_{2}, \alpha_{2}, f_{\mathrm{v} 2}\right)$.

Taking the total efficiency $\eta$ total maximum as the objective function,

$F\left(z_{1}, z_{2}, i_{1}, i_{2}, \alpha_{1}, \alpha_{2}, f_{1}, f_{2}, \delta, \beta\right)=\max \left(\eta_{\text {total }}\right)$

The values of the friction factors $f_{1}$ and $f_{2}$ vary according to the application and cost, and this optimization is set to 0.01 for both. Combined with the actual situation, the constraints are listed as follows.

$$
\begin{aligned}
& 14 \leq z_{1} \leq 30 ; 11 \leq z_{2} \leq 30 \\
& i_{1}<i_{2}-10<0.2 ; 1<i_{1}<10 ; 1<i_{2}<10 \\
& 15^{\circ}<\alpha_{1}<25^{\circ} ; 15^{\circ}<\alpha_{2}<25^{\circ} \\
& f_{1}=0.01 ; f_{2}=0.01 ; 8^{\circ}<\beta<25^{\circ} \\
& \delta_{1}=\arctan i_{1}
\end{aligned}
$$

The penalty function outer point method is still used, and the initial point I0 $\left(z_{1}=z_{2}=20, i_{1}=3, i_{2}=3.3, \alpha_{1}=\alpha_{2}\right.$ $=20^{\circ}, f_{1}=f_{2}=0.01, \delta=18.4^{\circ}, \beta=13^{\circ}$ ), the initial value of the penalty factor $r_{0}=1$, the amplification factor $c=10$, and the convergence accuracy $\varepsilon=0.001$.

The data is rounded, and the parameters of the bevel gear transmission driving wheel in the two-stage conecylindrical reducer are: $z_{1}=14 ; i_{1}=3.3 ; \alpha_{1}=20^{\circ} ; f_{1}=0.01$; $\delta=17$. The parameters of the driving wheel of the helical gear drive are: $z_{2}=26 ; i_{2}=3.3 ; \alpha_{2}=21^{\circ}, f_{2}=0.01 ; \beta=11^{\circ}$.

Comparing the efficiency values before and after optimization, the theoretical values of the abovementioned two types of gear transmission efficiency have both increased by more than $11 \%$. With reference to the above optimization results, a two-stage cone-cylindrical reducer was designed and manufactured with a total transmission ratio of 11 , the teeth number of the bevel gear main and driven gear were 14, 46, and the number of teeth of the helical gear main and driven gear were 21 , and 70 . The rated input speed is at $2450 \mathrm{r} / \mathrm{min}$, rated output torque $2600 \mathrm{Nm}$. After testing by the testing organization under different test items, it is determined that the efficiency of 
the reducer in load performance test, gear contact fatigue life test and reliability test are $94.9 \%, 94.5 \%$ and $94.4 \%$, respectively.

From the optimization results of the first-stage spur gear transmission and the second-stage cone-cylindrical gear transmission and the actual test results, it can be seen that the relevant parameters obtained by optimization are within a reasonable range, and the bevel gears and helical gears are converted into equivalent spur gears. The method of optimized calculation is feasible [16].

\subsection{Measurement of Efficiency}

This paper identifies the driving and driven relationship of the gear, and the direction of power flow.

According to the loading direction of Fig. 2 and the meshing of the gears and the direction of rotation of the motor, it can be seen from Fig. 5 that gear a is active, a pushes $b$, c pushes $d$, and its power flows in the direction $\mathrm{a} \rightarrow \mathrm{b} \rightarrow \mathrm{c} \rightarrow \mathrm{d}$. When the rotation direction of the motor is opposite, gear $\mathrm{d}$ is active, $\mathrm{c}$ is driven, and the power flow direction is reversed. Therefore, for a closed test bench, it can be determined whether the gear is driving or driven according to the direction of the loading torque and the rotation of the motor.

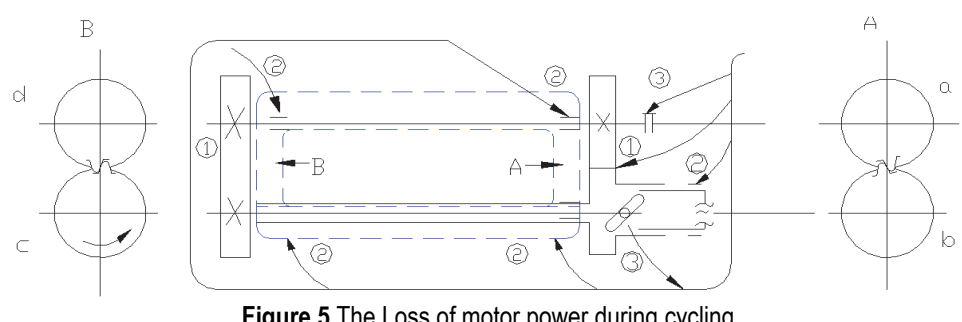

Figure 5 The Loss of motor power during cycling

In Fig. 5, (1), 2), and (3) respectively represent the loss of the motor power consumed in gears, bearings, and couplings during the cycle.

When measuring and calculating efficiency, power is often converted into torque, and take:

(1) When the output power of the motor is $P_{1}$, it is completely consumed to overcome the friction loss of the closed system, that is, $P_{1}=P_{5}$.

(2) Take the efficiency of two pairs of gears as $\eta_{\mathrm{a}-\mathrm{b}}=\eta_{\mathrm{c}-\mathrm{d}}=\eta, \eta$ means the average efficiency

When gear a is active, power flows from a to $d$. Since wheel $\mathrm{d}$ is the end of the closed power flow (output end), then:

---Closed power - For gear $\mathrm{c}-\mathrm{d}: P_{\mathrm{i}}=P_{\mathrm{B}}$

---Closed power - For gear c $-\mathrm{d}$ :

Or $T_{\mathrm{c}}=\frac{T_{\mathrm{B}}}{\eta_{\mathrm{c}-\mathrm{d}}}$

For gear a and gear b: $\eta_{\mathrm{a}-\mathrm{b}}=\frac{T_{\mathrm{b}}}{T_{\mathrm{a}}}=\frac{T_{\mathrm{c}}}{T_{\mathrm{a}}}=\frac{T_{\mathrm{B}}}{\eta_{\mathrm{c}-\mathrm{d}} T_{\mathrm{a}}}$

Or $T_{\mathrm{a}}=\frac{T_{\mathrm{B}}}{\eta_{\mathrm{a}-\mathrm{b}} \eta_{\mathrm{c}-\mathrm{d}}}$.

Since the difference between the power at the beginning and the end of the closed power is the friction loss of the system, which is the output power $P_{1}$ of the motor, the output torque $T_{1}$ can be directly measured from the balance motor, then:

Or $\eta_{\mathrm{a}-\mathrm{b}} \eta_{\mathrm{c}-\mathrm{d}}=\frac{T_{\mathrm{B}}}{T_{\mathrm{B}}+T_{1}}$.

Then the average efficiency is,

$\eta=\sqrt{\eta_{\mathrm{a}-\mathrm{b}} \eta_{\mathrm{c}-\mathrm{d}}}=\sqrt{\frac{T_{\mathrm{B}}}{T_{\mathrm{B}}+T_{1}}}$.

When gear $d$ is active, the power flow is reversed and becomes $\mathrm{d} \rightarrow \mathrm{c} \rightarrow \mathrm{b} \rightarrow \mathrm{a}$, and gear $\mathrm{a}$ is the end of the power flow. At this time, the enclosed power is greater than the transmitted power, and the friction power supplied by the motor is as follows or $T_{1}=T_{\mathrm{B}}\left(1-\eta^{2}\right)$.

Hence, $\eta=\sqrt{\frac{T_{\mathrm{B}}-T_{1}}{T_{\mathrm{B}}}}$.

It can be seen from the efficiency formula that as long as the output torque of the motor and the applied closing torque can be measured actually, the efficiency of the closed transmission can be measured.

\section{RECORD OF EXPERIMENTAL RESULTS 4.1 Optimization Results}

After the optimization, the optimized values of the design variables were adjusted and the unit characteristics were redefined. Then, the same analysis method was used to analyze the dynamic response.

The calculation results of dynamic response analysis show that the transfer acceleration of each corresponding point on the surface of the box body is reduced to some extent after optimization, and the maximum reduction is $41.7 \%$. Among them, the transfer acceleration of the lower box body is greatly reduced. The acceleration reduction amplitude of the high-speed shaft input end bearing seat and the low-speed shaft output end bearing seat is greater than the acceleration reduction at the other end, and the transfer acceleration change amplitude of the upper box body close to the high-speed shaft is smaller.

The specific results after optimization are shown in Tab. 4. After optimization, the transfer speed in the multistage gear transmission system has reduced. The rootmean-square value of the transfer acceleration of the transmission system components has reduced by $36.8 \mathrm{~m} / \mathrm{s}^{2}$ on average, which is $33.5 \%$ less than before optimization, achieving the purpose of transfer reduction. The quality of the transmission system is reduced to $2532 \mathrm{~kg}, 12.96 \%$ less than before optimization. 


\begin{tabular}{|c|c|c|c|c|c|c|}
\hline \multicolumn{7}{|c|}{ Table 2 Test of Gear-belt drive } \\
\hline$M_{1}$ & $n_{1}$ & $P_{1}$ & $M_{2}$ & $n_{2}$ & $P_{2}$ & $u$ \\
\hline 4.04 & 1471.7 & 0.64 & 0.48 & 2205.8 & 0.18 & 0.18 \\
\hline 3.99 & 1471.7 & 0.63 & 0.52 & 2205.7 & 0.13 & 0.19 \\
\hline 4.06 & 1471.4 & 0.62 & 0.53 & 2205.4 & 0.16 & 0.19 \\
\hline 4.06 & 1471.4 & 0.61 & 0.59 & 2205.4 & 0.17 & 0.27 \\
\hline 4.13 & 1470.7 & 0.64 & 0.65 & 2204.1 & 0.13 & 0.26 \\
\hline 4.40 & 1468.9 & 0.68 & 0.87 & 2201 & 0.19 & 0.24 \\
\hline 4.73 & 1466.6 & 0.74 & 1.04 & 2197.2 & 0.24 & 0.31 \\
\hline 5.28 & 1463 & 0.82 & 1.39 & 2190.8 & 0.34 & 0.35 \\
\hline 5.64 & 1460.1 & 0.87 & 1.62 & 2186 & 0.37 & 0.43 \\
\hline 7.82 & 1444.3 & 1.18 & 2.98 & 2159.5 & 0.68 & 0.58 \\
\hline 8.46 & 1439.3 & 1.28 & 3.45 & 2151.2 & 0.77 & 0.62 \\
\hline 8.86 & 1436.4 & 1.34 & 3.67 & 2164.1 & 0.84 & 0.62 \\
\hline 8.25 & 1433.2 & 1.37 & 3.94 & 2141 & 0.89 & 0.64 \\
\hline 9.57 & 1430.5 & 1.47 & 4.16 & 2136.3 & 0.95 & 0.64 \\
\hline 10.61 & 1422.2 & 1.59 & 4.85 & 2122.3 & 1.07 & 0.68 \\
\hline
\end{tabular}

are inseparable. However, the transmission efficiency of Fig. 6 and Fig. 7 has different increasing trends with the growth of power. However, the overall increasing trend of the efficiency in Fig. 6 with the power is slower, and the efficiency in Fig. 7 increases rapidly with the power at the initial stage. But the subsequent increase in power is slower than in Fig. 6.

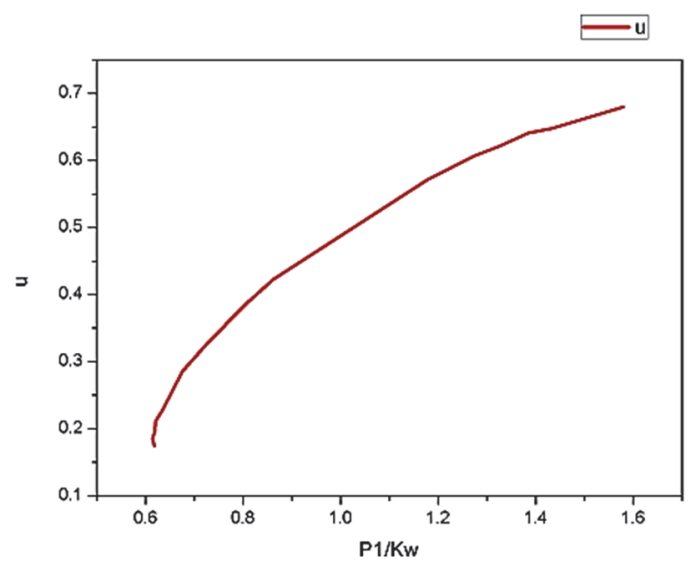

Figure 6 Power-efficiency diagram of gear-belt transmission

\begin{tabular}{|c|c|c|c|c|c|c|}
\hline$M_{1}$ & $n_{1}$ & $P_{1}$ & $M_{2}$ & $n_{2}$ & $P_{2}$ & $u$ \\
\hline 3.27 & 1480.4 & 0.58 & 0.47 & 2216.3 & 0.18 & 0.21 \\
\hline 3.28 & 1480.4 & 0.53 & 0.45 & 2216.2 & 0.15 & 0.28 \\
\hline 3.34 & 1480 & 0.56 & 0.52 & 2215.4 & 0.18 & 0.21 \\
\hline 3.46 & 1479.1 & 0.57 & 0.6 & 2213.8 & 0.15 & 0.27 \\
\hline 3.76 & 1477.3 & 0.58 & 0.77 & 2210.4 & 0.15 & 0.32 \\
\hline 4.19 & 1474.4 & 0.64 & 1.08 & 2205.2 & 0.22 & 0.38 \\
\hline 4.86 & 1469.7 & 0.76 & 1.49 & 2197 & 0.39 & 0.47 \\
\hline 5.65 & 1464.4 & 0.83 & 1.99 & 2187.2 & 0.48 & 0.53 \\
\hline 6.58 & 1457.6 & 1.04 & 2.66 & 2175 & 0.62 & 0.58 \\
\hline 7.51 & 1450.8 & 1.19 & 3.25 & 2162.2 & 0.72 & 0.63 \\
\hline 9.07 & 1439.3 & 1.36 & 4.24 & 2140.2 & 0.98 & 0.71 \\
\hline 10.83 & 1425.5 & 1.61 & 5.44 & 2110.9 & 1.09 & 0.74 \\
\hline 14.86 & 1390.7 & 2.17 & 8.61 & 1967.4 & 1.68 & 0.78 \\
\hline
\end{tabular}

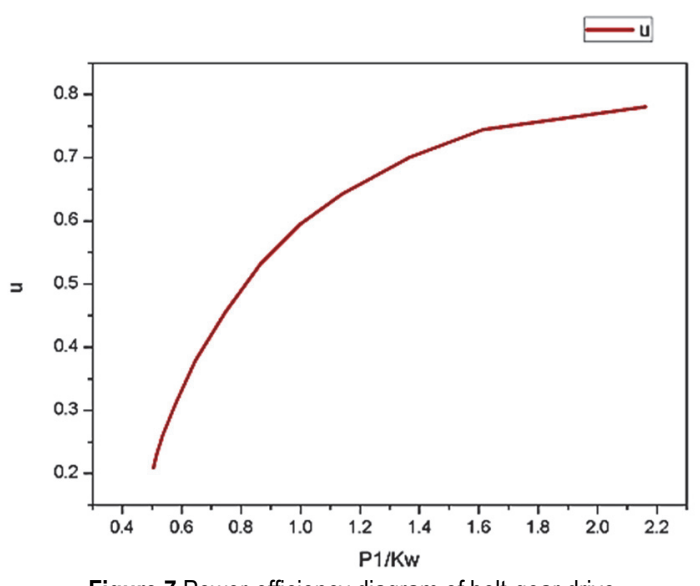

Figure 7 Power-efficiency diagram of belt-gear drive

Compared with the two transmission arrangements shown in Fig. 6 and Fig. 7. Fig. 7 is more reasonable. The belt in Fig. 7 is arranged at a high-speed level directly connected to the motor, which can cushion shock absorption and overload slippage, and has better starting performance. If the arrangement shown in Fig. 6 is adopted, the belt transmission is at a low speed, and the transmission torque at low speed is small and slipping is easier.

Table 4 Optimization results of various parameters
\begin{tabular}{|c|c|c|c|c|c|c|c|}
\hline Optimization & $M_{1}$ & $z_{1}$ & $z_{2}$ & $b_{1}$ & $\beta_{1}$ & $\mathrm{M}_{2}$ & $b_{2}$ \\
\hline Initial value & 12 & 45 & 48 & 148 & 12 & 14 & 136 \\
\hline Optimization value & 6 & 96 & 112 & 142 & 6 & 7 & 132 \\
\hline Optimization & $\beta_{2}$ & $z_{3}$ & $z_{4}$ & $M_{3}$ & $\beta_{3}$ & $z_{5}$ & $z_{6}$ \\
\hline Initial value & 8 & 12 & 24 & 16 & 12 & 46 & 48 \\
\hline Optimization value & 6 & 10 & 20 & 12 & 6 & 94 & 92 \\
\hline
\end{tabular}

\subsection{Analysis and Processing of Experimental Results}

It can be seen from the two figures that no matter which arrangement is used, the transmission efficiency shows an increasing trend with the growth of power, and the increasing trend gradually slows down. The reason for this phenomenon is that the belt is an elastic body and when the force is different. The unequal elongation makes the belt drive elastic sliding, and efficiency and elastic sliding

\section{CONCLUSIONS}

The gear system is a high-speed rotating part, and the speed has a great influence on the system mode, this method has certain errors. In this paper, based on the modal analysis of structural dynamics, the first 10 modal frequencies and corresponding modes of the accessory drive system are obtained ignoring the external excitation and only considering the modal analysis of the gear system with internal excitation. After the performance optimization, the parameterized gear system model can also make corresponding adjustments according to the corresponding optimization parameters, laying a foundation for the design of high-quality gear transmission 
systems.

From the above discussion, it can be seen that the analysis and research of gear transmission transfer and the optimization design research of dynamic performance have received more and more attention. For the design of mechanical products, more attention should be paid to its dynamic performance rather than the traditional static performance. Only in this way, the gear transmission device designed is closer to its actual working state and has higher reliability.

\section{Acknowledgments}

The work is supported by Jiangsu Qing Lan Project; Research topics in education and teaching of Changzhou University Huaide College (No:2019HDJY16); Jiangsu Key Laboratory of Green Process Equipment.

\section{REFERENCES}

[1] Chen, H., Fan, J., Jing, S., \& Wang, X. (2019). Probabilistic design optimization of wind turbine gear transmission system based on dynamic reliability. Journal of Mechanical Science and Technology, 33(2), 579-589. https://doi.org/10.1007/s12206-019-0112-9

[2] Xiang, L., Zhang, Y., Gao, N., Hu, A., \& Xing, J. (2018). Nonlinear dynamics of a multistage gear transmission system with multi-clearance. International Journal of Bifurcation and Chaos. https://doi.org/10.1142/S0218127418500347

[3] Fernández-del-Rincón, A., Iglesias, M., de-Juan, A., DiezIbarbia, A., García, P., \& Viadero, F. (2016). Gear transmission dynamics: Effects of index and run out errors, Applied Acoustics, 108, 63-83. https://doi.org/10.1016/j.apacoust.2015.11.012

[4] Bel Mabrouk, I. \& El Hami, A.(2019). Effect of number of blades on the dynamic behavior of a Darrieus turbine geared transmission system. Mechanical Systems and Signal Processing, 121, 562-578. https://doi.org/10.1016/j.ymssp.2018.11.048

[5] Xi, J. Q., Tang, G. Q., Zhai, Y., Zhang, G. X., \& Gu, H. T. (2016). Analysis on the gear-shifting schedule of hydraulic automatic transmission. Journal of Beijing Institute of Technology, 25(1), 42-48.

[6] Xiang, L., Gao, N., \& Hu, A. (2017).Dynamic analysis of a planetary gear system with multiple nonlinear parameters. $J$. Comput. Appl. Math. https://doi.org/10.1016/j.cam.2017.06.021

[7] Xi, J. Q., Tang, G. Q., Zhai, Y., Zhang, G. X., \& Gu, H. T. (2016). Analysis on the gear-shifting schedule of hydraulic automatic transmission. Journal of Beijing Institute of Technology, 25(1), 42-48.

[8] Zhou, H., Liu, H., Gao, P., \& Xiang, C. L. (2018). Optimization design and performance analysis of vehicle powertrain mounting system. Chinese Journal of Mechanical Engineering, 31(02), 76-88. https://doi.org/10.1186/s10033-018-0237-2

[9] Ling, M. A. (2019). Test and analysis of coupled dynamic performance of automotive mechanical transmission. Journal of Heze University.

[10] Chen, Q., Wang, Y., Tian, W., Wu, Y., \& Chen, Y. (2019). An improved nonlinear dynamic model of gear pair with tooth surface microscopic features. Nonlinear Dynamics. https://doi.org/10.1007/s11071-019-04874-1

[11] Zaigang, C., Wanming, Z., \& Kaiyun, W. (2019). Transfer feature evolution of locomotive with tooth root crack propagation of gear transmission system. Mechanical Systems and Signal Processing, 115, 29-44. https://doi.org/10.1016/j.ymssp.2018.05.038.

[12] Lu, X., Li, Z., Guo, L., Gao, B., Zhang, N., \& Chuanxue, S. (2018). Optimization of gearshift MAP based on DP for vehicles with automated transmission. Science China(Information Sciences), 61(11), 247-249. https://doi.org/10.1007/s11432-017-9317-x

[13] Yang, J. J., Shi, Z. H., Zhang, H., Li, T. X., \& Wei, B. Y. (2018). Dynamic analysis of spiral bevel and hypoid gears with high-order transmission errors. Journal of Sound and Transfer, 417, 149-164. https://doi.org/10.1016/j.jsv.2017.12.022

[14] Ylmaz, T. G., Doan, O., \& Karpat, F. (2019). A comparative numerical study of forged bi-metal gears: bending strength and dynamic response. Mechanism and Machine Theory, 141, 117-135. https://doi.org/10.1016/j.mechmachtheory.2019.07.007

[15] Wu, J., Walker, P. D., Ruan, J., \& Zhang, N. (2017). Target torque estimation for gearshift in dual clutch transmission with uncertain parameters. Applied Mathematical Modelling, 51, 1-20. https://doi.org/10.1016/j.apm.2017.06.030

[16] Cai, Y., Yao, L., Xie, Z., Zhang, J., \& Peng, C. (2017). Influence analysis of system parameters on characteristics of the nutation drive with double circular arc spiral bevel gears. Forschung auf demGebiete des Ingenieurwesens, 81(2-3), 125-133. https://doi.org/10.1007/s10010-017-0245-x

\section{Contact information:}

\section{Lingyan ZHANG}

Changzhou University Huaide College,

Jingjiang, 214500, P. R. China

Jiangsu Key Laboratory of Green Process Equipment,

Changzhou, 213164, P. R. China

E-mail: zhanglingyan_czuh@163.com

\section{Shuicai QIU}

(Corresponding author)

Changzhou University Huaide College,

Jingjiang, 214500, P. R. China

Jiangsu Key Laboratory of Green Process Equipment,

Changzhou, 213164, P. R. China

E-mail: qiushuicai_czuh@163.com 